\title{
Emotionality changes following septal and neocortical ablations in the albino rat'
}

\author{
SUSAN M. CLARK, PATRICIA M. MEYER, DONALD R. MEYER, AND DAVIO A. YUTZEY?
}

OHIO STATE UNIVERSITY

Albino rats with neocortical-septal lesions exhibited the sustained emotionality following a three week recovery period that has been observed in hooded Ss. The maintenance of this behavior could not be accounted for in terms of locus or laterality of the neocortical lesion.

Hooded rats with simultaneous septal-neocortical ablations maintain a state of hyperemotionality if left undisturbed for a three week recovery period. Such is not the case for control animals that have sustained either a septal lesion or a neocortical ablation, for these rats are similar to normal animals in their affective behavior following the 21-day postoperative interval (Yutzey, Meyer, \& Meyer, 1964; Yutzey, Meyer, \& Meyer, in press).

The present experiment was designed to test whether the maintenance of hyperemotionality obtained by Yutzey, Meyer, \& Meyer (in press) could be replicated in the albino rat, particularly since recent data have indicated behavioral and anatomical differences between these two strains of rats (Sheridan, 1965; Lund, 1965; Meyer, Yutzey, \& Meyer, 1966). In addition, we tested whether the sustained emotionality could be attributed to locus or laterality of the neocortical ablation.

\section{Subjects and Procedure}

One hundred fifty-one albino rats of the HarlanWistar strain were rated for six consecutive days on the emotionality scale devised by King (1958). Each $S$ was evaluated on (1) reaction to a pencil presented close to the snout, (2) response to a light tap on the back with the pencil, (3) resistance to capture, (4) resistance to handling, (5) vocalization during capture and handling, and (6) urination and defecation in reaction to capture and handling. Following completion of preoperative ratings, all Ss except for a normal control group were subjected to surgery. The experimental groups consisted of rats with combined lesions of bilateral anterior neocortex and septum, bilateral posterior neocortex and septum, and complete unilateral neocortex and septum. The control Ss had ablations of bilateral anterior neocortex, bilateral posterior neocortex, and unilateral neocortex. These groups were allowed three weeks for recovery. Two more groups were subjected to lesions of the septal forebrain and they received either two or 21 days of recovery. Following recovery, emotionality ratings were resumed for six consecutive days.

All neocortical surgery was performed by aspiration, and septal lesions were made electrolytically with the aid of the de Groot atlas (1959). After the postoperative observations were completed, Ss were perfused with $10 \%$ formalin, and their brains were removed, embedded in celloidin, serially sectioned, and stained with cresyl violet.

Results

Mean and median emotionality scores for all groups are shown in Table 1 for the last rating day (Day 6) prior to surgery and for the first postoperative rating day (Day 1 F) following recovery from surgery. Standard errors of the mean also were computed for all groups on Day $1 \mathrm{~F}$.

Statistical comparisons between the cortical-septal groups and their respective cortical-control groups and between the cortical-septal groups and the septalthree-week recovery group were made by means of Mann-Whitney $U$ tests. The results of the analyses were: (1) septal-unilateral group vs unilateral group, p<.02; septal-posterior group vs posterior group, $p=.09$; septal-anterior group vs anterior group, $p<.02$; septal-unilateral group vs septal-three-week group, p<.05; septal-posterior group vs septal-three-week group, $\mathrm{p}<.05$; septal-anterior group vs septal-threeweek group, $\mathrm{p}<.02$.

Histological reconstructions revealed that the lesions of the septal area in the albino Ss were similar to the hooded Ss in the Yutzey, Meyer, \& Meyer (1964) and the Yutzey, Meyer, \& Meyer (in press) experiments. Damage was most often observed in the Nucleus septi lateralis, Nucleus septi medialis, corpus callosum, Fornix precommisuralis, Nucleus triangularis septi, Columna fornicis, Nucleus septalis fimbrialis, and Tractus diagonalis (Broca).

Approximately 30 to 50 percent of the neocortex had been removed in the anterior half of the neo-

Table 1. Mean and median emotionality ratings for all groups on the last preoperative and on the first postoperative rating days.

\begin{tabular}{|c|c|c|c|c|}
\hline$N$ & Group & $\begin{array}{l}\text { Day } 6 \\
\text { Mean/Median }\end{array}$ & $\begin{array}{l}\text { Day } / F \\
\text { Mean/Median }\end{array}$ & $\begin{array}{c}\text { Stgndard } \\
\text { Error }\end{array}$ \\
\hline 18 & Sept.-post. & $5.64 / 5.40$ & $11.99 / 14.42$ & 1.15 \\
\hline 11 & Sept-ant. & $6.02 / 5.85$ & $12.58 / 12.85$ & 1.03 \\
\hline 17 & Sept.-unilat. & $6.08 / 6.02$ & $12.00 / 12.48$ & 1.01 \\
\hline 15 & Sept-2-day & $5.79 / 5.90$ & $10.37 / 10.65$ & 1.05 \\
\hline 10 & Sept-3-week & $5.97 / 5.78$ & $8.32 / 8.38$ & .87 \\
\hline 10 & Anterior & $5.99 / 5.58$ & $8.77 / 7.58$ & 1.00 \\
\hline 10 & Normal & $5.72 / 5.45$ & $7.98 / 7.58$ & .67 \\
\hline$n$ & Unilateral & $5.56 / 5.35$ & $7.52 / 7.30$ & .49 \\
\hline 11 & Posterior & $5.86 / 5.65$ & $7.98 / 7.10$ & 1.12 \\
\hline
\end{tabular}


Table 2. Comparison of emotionality ratings between hooded rats in the Yutzey, Meyer \& Meyer experiment (in press) and albino rats in the present experiment on the first postoperative rating day.

$\begin{array}{lrc}\text { Group } & \text { Hooded Rats } & \text { Albino Rats } \\ \text { Septal-anterior } & 14.12 & 12.85 \\ \text { Anterior } & 7.00 & 7.58 \\ \text { Septal-posterior } & 13.75 & 14.42 \\ \text { Posterior } & 8.35 & 7.10 \\ \text { Septal-3-week-recovery } & 6.70 & 8.38\end{array}$

cortex and in the posterior half of the neocortex for those Ss subjected to bilateral neocortical ablations. Approximately 80 to 95 percent of the neocortex in one hemisphere had been ablated in those Ss with unilateral neocortical removals.

Animals that were excluded from the data analysis were those with no bilateral damage to the lateral nuclei of the septum, those with no damage to the medial nucleus of the septum, and those in the cortically lesioned groups that had bilateral subcortical damage. Discussion

Albino rats with ablations of either the anterior or posterior neocortex in combination with a septal lesion exhibit the sustained hyperreactivity after 21 days that Yutzey, Meyer, \& Meyer (in press) reported for hooded Ss. Table 2 shows that either hooded or albino rats with septal-anterior or septal-posterior lesions are hyperemotional when compared to their respective cortical and septal control groups.

The albino rats that were allowed only two recovery days tended to be more emotional $(10.65)$ than normal (7.58) and septal-three-week recovery Ss (8.38), but this result was not statistically significant. In contrast, we have found that hooded septal-two-day recovery animals are consistently more hyperreactive when compared to control Ss (Yutzey, Meyer, \& Meyer, 1964; Corman, Meyer, \& Meyer, submitted for publication).

We also studied the problem of the relationship between sustained septal emotionality and the locus or laterality of the neocortical ablation. Removal of approximately half of the neocortex in conjunction with a lesion of the septal forebrain was sufficient for maintaining hyperemotionality, but this behavior could not be attributed to the removal of a specific neocortical locus. Neither could we account for it in terms of laterality since both bilateral and unilateral neocortical ablations combined with a septal lesion resulted in sustained hyperreactivity.

\section{References}

Corman, C. D., Meyer, P. M., \& Meyer, D. R. Open-field activity and exploration in rats with septal and amygdaloid lesions. Submitted for publication.

de Groot, $J$. The rat forebrain in stereotaxic coordinates. Veh. Kon. Ned. Akad. Wet., 1959, 52, 1-40.

King, F. A. Effects of septal and amygdaloid lesions on emotional behavior and conditioned avoidance responses in the rat. $J$. nerv. ment. Dis., 1958, 126, 57-63.

Lund, R. D. Uncrossed visual pathways of hooded and albino rats. Science, 1965, 149, 1506-1507.

Meyer, D. R., Yutzey, D. A., \& Meyer, P. M. Effects of neocortical ablations on relearning of a black-white discrimination habit by two strains of rats. J. comp. physiol. Psychol., 1966, 61, 83-86.

Sheridan, C. L. Interocular transfer of brightness and pattern discriminations in normal and corpus callosum-sectioned rats. $J$. comp. physiol. Psychol., 1965, 59, 292-294.

Yutzey, D. A., Meyer, D. R., \& Meyer, P. M. Effects of simultaneous septal and neo- or limbic-cortical lesions upon emotionality in the rat. Brain Res., in press.

Yutzey, D. A., Meyer, P. M., \& Meyer, D. R. Emotionality changes following septal and neocortical ablations in rats. J. comp. physiol. Psychol., 1964, 58, 463-465.

Notes

1. The authors wish to express their appreciation to Dr. Charles Corman and Dr. Gordon Harding for their surgical assistance in the early phases of this experiment. This research was supported by the National Institutes of Health Grant MH-06211 while the last author was a predoctoral fellow under National Institutes of Health Training Grant 2M-6748-C4.

2. Now at Ohio Wesleyan University. 